\title{
American Academy of Pediatrics First Meeting of the Section of Rheumatology, November 1, 1981
}

IMMUNE COMPLEXES IN JUVENILE RHEUMATOID ARTHRITIS. H.S. Luthra, A.M. Nelson, and P.H. Wooley, Mayo Medical School, Rochester, MN. Although immune complexes have been implicated in the pathogenes is of adult rheumatoid arthritis, their role in juvenile rheumatoid arthritis remains unclear. We measured immune complexes by the monoclonal rheumatoid factor assay and the Raji Cell assay in 31 patients with juvenile onset rheumatoid arthritis. Of these 31 patients, 24 were females. The age at onset of the disease varied from 13 months to 15 years (mean 7.3 years) and the duration of disease at time of analys is varied from 4 months to 20 years (mean 6.6 years). Of the 31 patients, $12(39 \%)$
disease and $19(61 \%)$ had polyarticular disease.

By the monoclonal rheumatoid factor assay, we found $20(65 \%)$ of the patients to have immune complexes. The level of immune complexes correlated with disease activity and this was seen best in the polyarticular group. Density gradient fractionation revealed the measured material to be $19 \mathrm{~s}$ or larger in size.

Although $15(48 \%)$ of the patients were found to be positive by the Raji Cell assay, density gradient fractionation revealed the reacting dant cell cytotoxicity assay, 13 of 29 sera (45\%) showed anti-Raji Cell antibodies. These $7 \mathrm{~s}$ IgG antibodies can give false positive results.

We conclude that immune complexes measured by the monoclonal rheumatoid We conclude that immune complexes measured by the monoclonal rheu
factor assay are present in this disease and correlate with disease factor assay are present in this disease and correlate with disease
activity. The Raji Cell assay results are influenced by the presence activity. The Raji Cell assay results are influenced by the presence
of anti-Raji Cell antibodies. The significance of these antibodies needs further study.

PULSE STEROID THERAPY IN CHILDREN WITH DIFFUSE PROLIFERATIVE LUPUS NEPHRITIS. K.S. Barron, D.A. Person, E.J. Brewer, Jr., A.M. Robson, Baylor College of Medicine, Texas Children's Hospital, Houston; and Washingt on niversity School of Medicine, St. Louis Children's Hospital, St. Louis.
The prognosis of patients with diffuse proliferative lupus nephritis is generally poor and the majority of patients with this lesion develop progressive deterioration in renal function. Intravenous "pulses" of methylprednisolone have been advocated for the treatment of severe nephritis. In this study, 7 patients with biopsy proven diffuse proliferative lupus nephritis were treated with 6 daily pulses $(30 \mathrm{mg} / \mathrm{kg} / \mathrm{day}$, not to exceed $1 \mathrm{~g} / \mathrm{day})$, followed by oral prednisone. They were compared with patients with similar renal pathology treated with oral high dose predni-

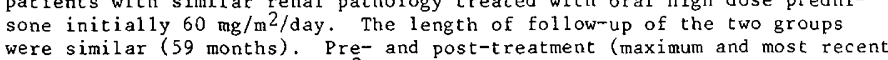
were similar $(59$ months $)$. Pre- and pos
values for GFR $\left(\mathrm{cc} / \mathrm{min} / 1.73 \mathrm{~m}^{2}\right)$ were:

$\begin{array}{cccc} & \text { Pre- } & \text { Post-(maximum) } & \frac{\text { Post }- \text { (most recent) }}{83+21} \\ \text { Pulse pts } & 52+16 & 82+18 & 86+18 \\ \text { High-dose pts } & 58+12 & 94+20 & \mathrm{~N} \overline{\mathrm{S}} \\ \quad \mathrm{p} & & .10>\overline{\mathrm{p}}>.05 & \end{array}$ $\mathrm{p}$
Pulse patients achieved maximum GFR at $17+11$ weeks compared to high-dose patients at $29+17$ weeks. This difference was statistically significant ( $p<.05)$ with a more rapid improvement in renal function in the pulse patients. There was a trend toward earlier return of C3 to normal in the pulse group but this trend was not statisically significant. No other laboratory or clinical differences were found between the two groups. There were no deaths in either. group. This study shows that there is a more rapid improvement in GFR following pulse therapy. However the long term effect on renal function of the two modes of therapy was the same.

VALUE OF SCINTIGRAPHY AND VASODILATOR MEDICATION IN REFLEX NEUROVASCULAR DYSTKOPHY (RND). R.W. Nickeson, D.A. Person, E.J. Brewer, R.E. Sonnemaker and S.E.

Seven children with reflex neurovascular dystrophy were seen and treated over a period of 6 months. Exquisite limb pain, hyperesthesia, and signs of vasomotor instability in a stocking glove distribution were invariably of vasomotor instability in a stocking glove distribution were invari
present. Joint-bone scan with technitium $99 \mathrm{~m}(99 \mathrm{~m} / \mathrm{Tc})$ pyrophosphate present. Joint-bone $s c$ an with technitium $99 \mathrm{~m}$ ( $99 \mathrm{~m} \mathrm{Tc}$ ) pyrophosphate
scintigrams immediately post-injection consistently showed decreased scintigrams immediately post-injection consistently showed decreased
perfusion to the affected areas. Delayed scans showed regional decreased bone uptake corresponding to the symptomatic region. The vasodilator medication, cyclandelate, relieved pain and dysfunction rapidly in 6 of the 7 children and was associated with more normal perfusion by $99 \mathrm{~m}$ Tc scan. Biopsies of affected skin and muscle during attacks consistently showed capillary pathology. Electron micrographs showed endothelial swelling and basement membrance thickening and reduplication. One girl's muscle had endomesial IgG deposits by immunofluoresence and patchy fiber atrophy and degeneration suggesting ischemia. We have been unable to find reports in the tnglish literature showing scintigrapnic evidence of decreased perfusion in KND. This new finding may reflect an early phase of the disorder with in RND. This new finding may reflect an early phase of the disorder with benericial and that scintigraphy to assess perfusion was diagnostically useful in children with RND. AN "EPIDEMIC" OF CHILDHOOD PSYCHOGENIC RHEUMATrSM. R.A. Doughty, J.C.
Harris, D. West, B.H. Athreya, Department of Pediatrics, University of Pennsylvania School of Medicine, Philadel phia.

Conversion reactions involving the musculoskeletal system occur in children and adolescents and may be severely incapacitating. This report describes an "epidemic" of arthralgia, myalgia and limp which occurred at a private girls' school in the Spring of 1976 with a recurrence in Spring, 1977. Eighteen girls were affected. Ten cases were identified the first year. Six of these recurred with an additional eight new cases in the year. Six
second year.

Symptoms were variable and included pain in the hips, knees, and feet. Mean duration of symptoms was 3.5 months for the first wave of the "epidemic." During the recurrence suspicion of a significant functional component prompted evaluation of recurrent cases by a pediatric rheumatologist. Despite impressive physical incapacity (use of crutches, wheel evidence of joint pathology on physical examination and screening labor-
ever atory studies were traumatic factors. Behavioral modification therapy led to resolution of each patient's symptoms, often dramatically, and within
two weeks in all cases. A single patient was seen with a recurrence on the two weeks in all cases. A single patient was seen with a recurrence on the case resolved promptly with reassurance alone. Follow-up three years later revealed no chronic joint disease among the 16 patients who were contacted. This "epidemic" points out the importance of recognizing conversion reaction as one of the etiologic factors in musculoskeletal symptoms in children. Prompt recognition and therapy of acute
subsequent morbidity resulting from overtreatment.

SOCIAL FUNCTION OF YOUNG ADULTS WHO HAD ARTHRITIS IN CHILDHOOD. J.J. Miller, III, P. Spitz, U. Simpson, and G.F. Williams, Children's Hospital thanford, Palo Alto

The current social and financial function of 121 young adults 18 years of age or older who had been seen at this hospital with juvenile arthritis since 1955 was determined by a series of questionnaires. The degree of their physical disability was measured by a validated method using a questionnaire and home visits. The modes of onset of their illnesses and the social circumstances of the family at the onset of the arthritis were determined by chart review and questionnaire. The group as a whole were functioning well: 45 were working full time, 25 were in school full time, 25 were in school and working, and 14 were married women at home. The levels of education which had been achieved matched those of the state of California in general and were only slightly behind that of the area immediately surrounding Stanford. Only two features at the onset of the disease were found to have an association with the outcome variables studied. Females had a higher prevalence of persisting disability, and patients who had had a polyarticular onset had lower monthly salaries, although they were not distinguishable at statistically significant levels by any of the other parameters examined. We did not find the expected association of poor prognosis with early presence of rheumatoid factor. Fifty of the pat ients were compared to matched siblings and were found to have achieved comparable educations, salaries, and proportionate numbers of marriages and children. We conclude that the social function of young adults who have had arthritis in childhood is generally good. CHRONIC ARTHRITIS PRESENTING IN THE NEONATE. S.G. Hassink, K. Dunn, M.
Reber, R. Truex, D.P. Goldsmith. St. Christopher's Hospital for Children, Reber, R. Truex, D.P. Goldsmith. St. Christopher's Hosp

We report 2 children who have developed chronic arthritis after presenting at birth with hepatitis, hepatosplenomegaly, anemia, transient thrombocytopenia, and a maculopapular rash. By the age of 5 months both children had persistent low grade fevers, soft tissue swelling and limitation of motion in multiple joints, diffuse adenopathy, and persistence of maculopapular rash. Radiologic changes included tnetaphyseal and epiphyseal erosions and periosteal elevation of the humeri, femurs and tibias.

Both children have continued to have chronic arthritis with markedly increased ESR; rheumatoid factor and antinuclear antibody have been negative, complement levels not decreased. Multiple bacterial. and viral studies have been negative. Neither child has developed eye lesions; each has remained below the third percentile for height and weight. One patient's course has below the third percentile for height and weight. One patient's course has been complicated by congestive heart failure and persistent left ventricumia. Circulating immune complexes have been detected during these exacerbations.

The other child, a male, also has chronic meningitis and external hydrocephalus. Metabolic studies revealed a markedly elevated urine sialic acid; cultured fibroblast neuraminidase activity, however, was normal, and not consistent with infantile sialidosis (a form of neuraminidase deficiency). The relationship of this abnormal urinary finding to the underlying disease
remains unclear. ins unclear.

Prieur and Griscelli ( $J$ Ped July 1981) have reported 3 patients with similar findings. These children may represent the neonatal onset of a chronic arthritis syndrome with multiple organ involvement which does not readily fit into the current classification system. We suspect that these diseas
manifestations may be a result of an undetected intrauterine infection. 